\title{
Approaches to the Ex-ante Evaluation of Investments into Information Systems
}

\section{The Authors}

\section{Sascha G. Walter Thorsten Spitta}

Dipl.-Kfm./MAIB Sascha G. Walter Christian-Albrechts-Universität Kiel Graduiertenkolleg "Betriebswirtschaftliche Aspekte lose gekoppelter Systeme und Electronic Business" 24098 Kiel

sascha.walter@bwl.uni-kiel.de

Prof. Dr.-Ing. Thorsten Spitta Universität Bielefeld

Fakultät für Wirtschaftswissenschaften Angewandte Informatik/Wirtschaftsinformatik

33501 Bielefeld

thSpitta@wiwi.uni-bielefeld.de investments, how to control the development and how to measure benefits after the implementation [FaLT99].

Overall research activities prevail through two broad streams. The first stream aims to directly measure the payoff of IS investments for organizations and comes to mixed conclusions [DeRi02]. The second stream addresses the question of how IS investments can actually be assessed by decision-makers and particularly focused on researching evaluation criteria, evaluation methods and the very nature of the evaluation process [Avge00].

Particularly, the field of evaluation methods has been criticized for being immature and fragmented $[\mathrm{MaSz} 99,491]$ which made academics call for "an overview of the whole panoply of evaluation methods, together with [...] the assumptions they de- pend on [... in order to enable...] the identification of gaps." [FaLT99, 205]. Another concern is a growing mismatch of theory and practice of ISE [ArIn99]. Although numerous techniques for IS evaluation prior to implementation (ex-ante evaluation) have been suggested in the academic literature, managers still draw some of their IS investment decisions on socalled "acts of faith", i.e. on their intuition and instincts [ReBe97; Fitz98]. These are worrying phenomena for proponents of rational decision-making.

Therefore, this paper (a) suggests a classification of proposed ex-ante evaluation approaches, (b) critically discusses samples of each class in terms of their scope of applicability and problem handling, and (c) provides an overview over empirical studies on ISE practice. Doing so, the state-of-

\section{Introduction}

A significant share of corporate funds is dedicated to the implementation, upgrading and maintenance of an information system (IS) which accounted for an averaged $8.8 \%$ of total corporate revenues in 2001 [CoSC01]. Consequently, a thorough evaluation of such investments is essential. However, even after more than two decades of research on IT controlling the normative literature still reports a great deal of difficulties in information system evaluation (ISE) [Iran02]. There are still serious concerns about how to select projects for

\section{Management Summary}

This paper classifies and critically reviews the currently available approaches for the ex-ante evaluation of investments into information systems. The effectiveness of the approaches is analyzed by means of general criteria and a brief overview of empirical studies is presented. Key findings include:

- The effectiveness of single methods is limited. The possibility of combining them is restricted by their bounded compatibility and in many cases by the effort involved.

- Indirect effects, qualitative factors and investment risk are insufficiently considered by most techniques.

- Approaches for the estimation of objective economic value prevail; social and political aspects are rather neglected.

- General evaluation problems (data collection, determining the reach of an information system, etc.) often reduce the methodological effectiveness.

- Few empirical studies on evaluation practices are available. They indicate a dominance of financial approache

Keywords: Information Systems, Information Technology, Evaluation, Value, Benefit, Performance, Success, Efficiency 
the-art of research on ISE methods is reflected on the basis of a comprehensive review of English and German literature. More than ten years after an initial overview of German work has been presented in this journal [Schu93], our article pays special attention to research in the AngloSaxon region, identifies special problems of ISE, particularly indicates strengths and weaknesses of ISE techniques, and analyzes actual empirical work.

\section{Thematic Background}

\subsection{Information Systems}

An information system is defined in this paper as an integrated socio-technical system with a certain life cycle that aims to provide information within organizations [StGR97, 336]. "Information" encapsulates knowledge for the purpose of taking effective action [Stic01, 2]. An IS as a special type of system can be characterized as being open, dynamic and complex. It can be subject to different types of investments: installation investments, add-on investments or replacement investments. Such investments can replace human labor to achieve calculable cost-savings (substitutive IS), can support human labor to generate estimatable increases of productivity (complementary IS), or can aim to realize competitive advantage [PaBe88, 103; Alpa02, 77].

A great deal of the difficulties associated with ISE stems from the characteristics of information and information systems. Determining the value of an IS as the worth of the information it provides is particularly troublesome. One reason is that information has no intrinsic value because its value depends on the associated purpose and varies between individuals and situations. Defining the value of information in relation to the decisions that can be based upon it is also problematic due to intervening factors such as the individual competencies of a manager to make use of certain information [FaLT93, 13]. Another reason is a fact known as "information paradox": in order to assess ex-ante an information's worth, its content has to be disclosed to determine the worth of the activities based on it after which there is no need to acquire the information anymore.

There are further key problems. First, the returns of investments in such systems can seldom be completely expressed in monetary terms because, being often of supportive nature, the system has a great distance to the cash flow generating activities of an organization [Hube99]. Second, the IS lifetime is hard to anticipate due to threats of technological obsolescence and changed organizational requirements [FaLT93, 13]. Third, information systems are often difficult to distinguish from each other, partly because of the growing crossorganizational integration of application systems [SmHi98] and partly because of the evolution of systems through modifications and extensions [CADF97]. Fourth, the realized value after an IS project is seldom exclusively attributable to a particular IS investment, but is due to compound effects such as a reorganization induced by an IS project [Anse84, 10]. Finally, IS investments often trigger not entirely predictable, organization-specific processes of change [CADF97]. These processes complicate reliable estimations because they can prevent the realization of expected benefits or can cause unforeseen costs [ChKa00].

\subsection{Evaluation of IS Investments}

IS evaluation is referred to as a process of determining by quantitative and/or qualitative means the value (explained below) of an IS investment to an organization [DoKi01]. Accordingly, evaluation approaches are supposed to analyze positive as well as negative impacts of such investments; methods for the mere estimation of software development costs [Hein96, 405] were thus not included in this review. In contrast to mere planning techniques, an ex-ante evaluation approach is understood as a procedure prior to the implementation of an IS in which criteria for the evaluation of an IS investment are prescribed or can be generated.

Several requirements of evaluation approaches have been suggested in the IS literature [Schu93]. They should facilitate an analysis of cost-savings, productivity increases and competitive advantage associated with an IS investment, in order to make the approach applicable for appraising substitutive, complementary and innovate information systems. Different types of investment impacts should be envisaged including quantitative financial, quantitative non-financial and qualitative factors. In addition, risk as well as the indirect effects involved in IS investments should be considered.

Academics have approached the topic of ISE from diverse research perspectives, ranging between two extreme positions: the formal-rational perspective and the in- terpretive perspective. The formal-rational perspective seeks the worth of an IS in a system's performance and financial profitability, whereby it emphasizes the economic and technical aspects. In contrast, the interpretive perspective focuses on the analysis and understanding of the social and subjective nature of ISE. Particularly, the interaction of the technology with organizational structures, culture and stakeholders is addressed [SeSm00]. As Table 1 illustrates, different types of evaluation approaches are related to both perspectives. It should be noted that the views are given as ideal types for illustrative purposes and to draw the attention to their contrasts whereas ISE in practice may take place between both extremes, reflecting their characteristics in varying proportions.

Ex-ante evaluation in general has to cope with a number of basic problems from which three problem types are primarily faced during formal-rational evaluation. The collection of accurate and complete data to appraise investment alternatives often causes considerable costs or is impossible at all [Anse84, 10], while forecasts as a consequence of the future-orientation of ex-ante evaluation are difficult due to the uncertainty involved. Moreover, judgmental bias might affect the evaluator's faculty of objective judgment, either unconsciously, when, for instance, an evaluator is susceptible to the persuasion of vendors and consultants [IrLo02] or when a project manager becomes too attached to her projects [FaLT93, 13], or consciously, where, for example, evaluation is used to rationalize already-made decisions instead of conducting an objective analysis. Other sources of judgmental bias are listed in [Hoga80, 165].

From the interpretive perspective, communication problems between evaluators can complicate the evaluation process due to divergent perspectives [SmHi98] which is not seldom the case between IT and business managers [AvCP99]. Moreover, stakeholder groups such as customers and vendors can exert substantial influence on evaluation processes [FaLT99] which requires the definition, analysis and involvement of such groups [Iran02].

\subsection{Value of IS Investments}

Defining evaluation as "determination of value", automatically raises the question of what is meant by "value". Often, this term is treated as being self-evident, thus remaining undefined, or is defined in one of any number of ways [BaRe00]. Since this 
Approaches to the Ex-ante Evaluation of Investments into Information Systems | 3

Table 1 Ideal Type Characterizations of Approaches to ISE [Adapted from JoHu0 I]

\begin{tabular}{ll}
$\begin{array}{l}\text { Formal-rational Approaches } \\
\begin{array}{l}\text { Concerned with ISE methods irrespective of } \\
\text { context }\end{array}\end{array}$ & $\begin{array}{l}\text { Interpretive Approaches } \\
\text { Concerned with context in which ISE takes place }\end{array}$ \\
\hline $\begin{array}{l}\text { Traditional mechanistic methods prevail } \\
\text { Economic factors dominate }\end{array}$ & $\begin{array}{l}\text { New interpretive methods are applied } \\
\text { Social factors dominate }\end{array}$ \\
\hline Legitimizes ISE process & $\begin{array}{l}\text { Engages with stakeholders in process to under- } \\
\text { stand assumptions and views }\end{array}$ \\
\hline Espouses single objective view & Seeks multiple-stakeholder subjective views \\
\hline Claims to be apolitical & Recognizes ISE as a political process \\
\hline Official, organizational view of ISE process & Unofficial, stakeholder view of ISE process
\end{tabular}

Table 2 Components of Value [Adapted from Renk00, 99]

\begin{tabular}{llll} 
Investment Impacts & Positive & Negative & Total \\
\hline Financial & Cash inflows & Cash outflows & Net cash flow \\
& Income & Expenditures & Net profit \\
\hline Non-financial & Positive contribution & Negative contribution & Net contribution \\
Total & Benefits & Sacrifices & Value \\
\hline
\end{tabular}

poses the danger of misinterpretation, a definition of value is proposed in the following section by subdividing the term "value" into single underlying components.

As shown in Table 2, the value of an IS investment consists of positive impacts (benefits) and negative impacts (sacrifices). These impacts are divided into monetarily measurable impacts (financial impacts) and non-monetary impacts (non-financial impacts). With respect to financial impacts, a further distinction is made between net cash flow and net profit. Net cash flows comprise the sum of cash inflows and cash outflows whereas net profit is defined as the accounting registration of income and expenditures. Regarding non-financial impacts, positive contributions of an IS investment and negative contributions are differed which are of either quantitative or qualitative nature.

The IS literature recognizes various benefits of IS investments that fall into three broad categories: efficiency, effectiveness and strategic advantage [Nage90, 24]. Costs classifications usually comprise costs for hardware, software and training at minimum $[\mathrm{MaFl00}]$ whereas more comprehensive taxonomies encompass additional items including maintenance costs and wider organizational costs such as costs for temporary job interruptions during a system transition or installation [HoGr91, 181].
The choice of the analysis level is another important issue for the estimation of IS value [Ahit80]. Essentially, the following levels of analysis were suggested in the literature: user, work group, department, business process, corporation and intercorporation [DaKa00]. Although ISE is per definition supposed to determine the value of an IS to the organization, several arguments were provided for including also or only levels below the corporate level: the validity of ISE could be increased through analyzing IS value at the locus of creation [WeHo96] and the corporate level could also be used as a starting point in order to stepwise envisage underlying levels [Schu93]. However, the selection of an appropriate analysis level may be a situationspecific decision as different types of IS investments may have different effects on corporate levels.

The use of value as the central evaluation criterion entails several problems for ISE. Identifying all benefits involved in an IS investment is difficult due to the indirect and unplanned effects of such actions [FaLT93, 13]. In addition, benefits and sacrifices are hard to estimate because they tend to evolve throughout the IS lifetime [SmHi98] or they are delivered with a certain time lag [BrHi98]. Moreover, the ambiguous concept of value lacks a universally accepted definition which could lead to misunderstandings [BaRe00], and there can be also conflicting perceptions of value in an organization [SmHi98].

\section{Critical Review of Evaluation Approaches}

\subsection{Antecedents to the Review}

A classification of all identified approaches is suggested in Figure 1. It synthesizes work of several authors [Schu93; IrLo02; ReBe97] and is oriented at the unit of analysis that each approach refers to. Due to the very different characteristics of the approaches, this classification is neither exhaustive nor mutually exclusive but fulfills its main function to construct a framework for an in-depth discussion of the techniques.

At the first level, effect-assessing approaches and effect-locating approaches are distinguished. The first type assumes the availability of necessary data and focuses on the calculation and description of investment impacts. The second type aims to locate those impacts as well as the respective data. Effect-assessing approaches are further subdivided into financial, indicator and multi-criteria approaches. Financial approaches exclusively consider financial factors such as cash flows, income and expenditures and calculate how advantageous an IS investment is from the financial perspective. Indicator approaches combine financial and quantitative non-financial factors to provide several measures or surrogates for "IS value". Multi-criteria approaches appraise IS investments by means of a score that is based on both financial and non-financial factors. Several approaches in the three classes can incorporate the analysis of risk by means of sensitivity analysis, scenario-techniques or probabilities [Schu93].

Regarding effect-locating approaches, the following four types are distinguished according to their focus. Business objectives-related approaches pursue an alignment of IS objectives to business objectives or to critical success factors in order to ensure effectiveness of the potential IS investment. Thus, investment proposals are assessed according to their impact on the achievement of business goals. Corporate processes-related approaches analyze possible IS investments with respect to their impacts on processes inside a corporation whereas customer-related approaches investigate the potential of IS investments to enhance customers' processes. Change man- 


\section{4 | Sascha G. Walter, Thorsten Spitta}

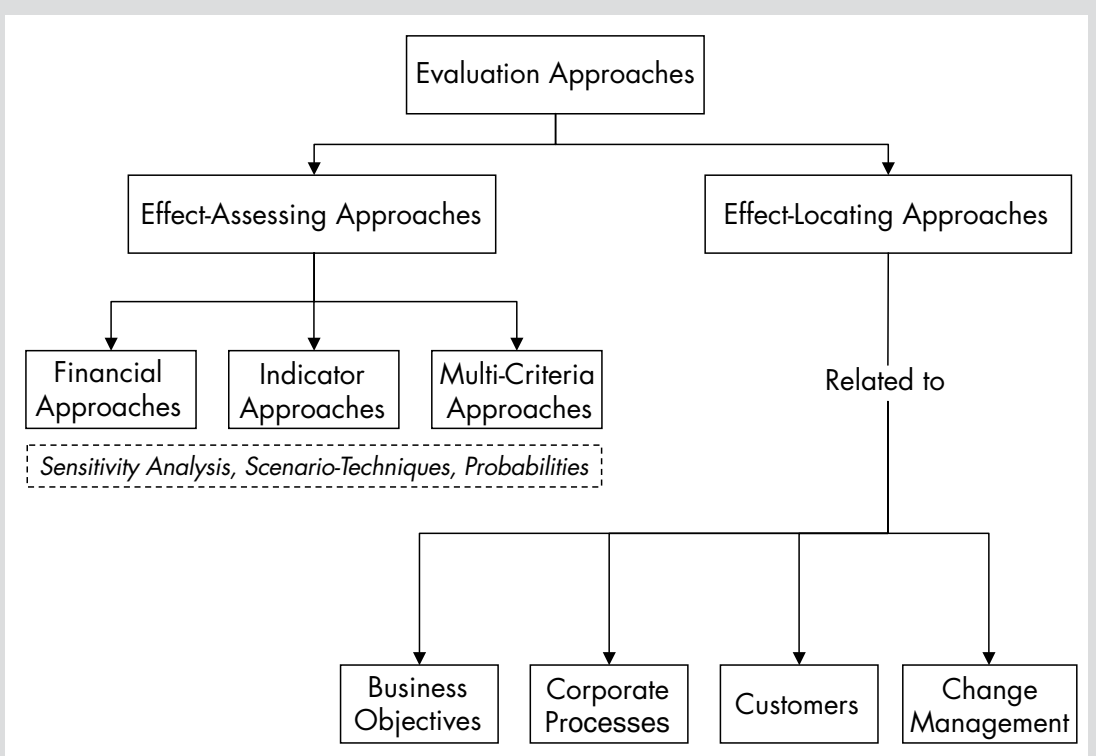

Figure 1 Classification of Evaluation Approaches of "IS value" and thus have to consider its quantitative and qualitative aspects alike. While quantitative aspects such as hardware costs tend to be directly measurable, qualitative aspects have to be indirectly measured via quantitative surrogates [BaRe96]. For reasons of measurement validity, each indicator should be based on a clear, comprehensive and homogenous definition [Tewa00]. Further, they should be up to date and there should be a likely causal relationship between the underlying represented factors [Sieg90, 30]. The literature generally recommends the interpretation of meaningful systems of indicators instead of isolated figures [BaRe96].

The use of indicators is advantageous for several reasons. They are relatively objective and easily communicable measures which can potentially bridge ex-ante and ex-post ISE [BaFr99]. However, they merely consider quantitative and quantifiable aspects of IS value, as qualitative aspects are either disregarded or represented by surrogates of often questionable validity [Arno95]. Furthermore, using comprehensive indicator systems can be costly in terms of data collection [Kütz99]. Another problem lies in the effective selection of the most important indicators [Sieg90, 123] for which little methodological support has been provided by IS research [Nage 90 , 152]. Moreover, the choice of desired values for indicators is often complicated because the respective underlying objectives might be conflicting, as it is the case for software development speed and quality [Kütz99]. Further difficulties include the appropriate interpretation of indicators and a blind, unconsidered faith in figures shown by many decision-makers [Sieg90, 124].

One example for an indicator-based evaluation concept is the balanced scorecard [KaNo92] modified for ISE purposes [GrBr97; ZeJo99]. Essentially, the scorecard supplements traditional financial evaluation of a corporation with measures concerning customer satisfaction, internal processes and the ability to innovate. They are produced through a process in which the management first defines a mission and then derives successively objectives and indicators from it [KaNo92]. As such the scorecard generates measures for the degree of goal achievement.

Translated to ISE, an IS department is seen as an internal service supplier with end-users as customers. In a version by [GrBr97], the original indicator groups are renamed into user orientation, corporate contribution, operational excellence and $f u$ - 
ture orientation. One objective in the group "corporate contribution" is, for instance, "control of IT expenses", measured as percentage deviation from the budget or by IT budget per turnover. Other contributions of indicator approaches are King's method [KiRo78], the 4-level model [Pico87, 105], boundary values [FaLT93, 103] and integrated key figures [BaFr99].

Overall, the balanced scorecard for ISE can be criticized for the same points as indicators in general, as it suffers from measurement and construct validity problems [Tewa00]. Its advantages are that it attempts to focus on the most central measures [KaNo92] and intends to combine financial and non-financial as well as past and future-oriented indicators in a holistic way. It can also enhance the overall IS planning speed and the communication between IS executives and business executives through a harmonization of objectives and actions [ZeJo99].

\subsubsection{Multi-Criteria Approaches}

This class is represented by the simple multi-attribute rating technique (SMART) and information economics. SMART's main objective is to permit a ranking of alternative courses of action by assigning a score to each founded on criteria and preferences stated by one or several decision-makers. A more detailed description of this widely applied concept can be found in [GoWroO, $18]$.

Advantages of SMART are the comprehensibility and transparency of the procedure. The method intends to objectify evaluation activities and fosters a consensus on the key assessment criteria by means of a thorough exploration of alternatives and preferences [FaLT93, 110]. Applying this method however requires much time for discussion and effort for data collection [Nage90, 97]. It can provide a fairly vague assessment when all details and complexities of the problem are not captured [GoWroo, 18]. This can also result in an insufficient consideration of monetary aspects [Rett96, 27]. Although intendedly objective, the method is still based on subjective preferences [Stic01, 80]. The comparison criteria might not be independent from each other, or could even be conflicting. Moreover, in cases of differing preferences of the evaluators no truly democratic system exists to resolve such differences [GoWr00, 303].

Information economics (IE) $[\mathrm{PaBe} 88,89]$ is a variant of cost-benefit analysis and enables a ranking of alternative projects by assigning one score to each. The respective scores are computed by adding up three situation-specifically weighted measures: simple ROI, business domain and technology domain. Consequently, pre-defined financial criteria are combined with criteria from the perspective of IT users (business domain) and IT suppliers (technology domain) such as the corporate IS department. These measures themselves are a sum of criteria including strategic match and technological uncertainty on which an overview can be found in [Renk00, 110]. Scores are assigned to each measure, ranging from 0 to +5 for a positive contribution and from 0 to -5 for factors reflecting risk.

Regarding advantages, IE is a detailed concept that prescribes evaluation criteria and their domains. Evaluators can therefore directly apply the method without having to agree on their own criteria. While involving business and technology managers alike, it promotes consensual decisions and understanding among management units $[\mathrm{PaBe} 88,16]$. Some notions of the concept are also usable without employing the full rigor of the method [FaLT93, 106]. On the other hand, IE requires considerable expertise in application and is expensive in use due to its in-depth analysis which might make it too complex for the appraisal of simple systems [FaLT93, 106]. Some of its concepts are too vaguely defined for a direct application. The prescription of evaluation criteria is in general deterministic and might prove to be too rigid in some situations. Further members of this class are the Scandinavian 'ISAC' [LuGN79], Buss' model [Buss83], Bedell's method [Bede85, 34], 'SESAME' [Linc88], 'FAOR' [Schä88, 181], knowledge-based system [AgTD92], the WARS model [Ott93], the analytical bierarchy process [GoWrO0, 387] and the IS portfolio [Krcm03, Ch.3.2].

\subsection{Effect-Locating Approaches}

\subsubsection{Business Objectives-Related Approaches}

A typical example for business objectivesrelated approaches is the model by Nolan, Norton E Company (NNC) [Nage90, 105] which describes a procedure for the purposeful allocation of an IS budget to investment areas according to their strategic importance. The model draws on the notion that information systems have to support the attainment of corporate objectives and is divided into three stages: (a) definition of corporate objectives, (b) identification of success factors and (c) identification of investment opportunities.

The first stage comprises the formulation of corporate objectives that have to be supported by an IS. They are assigned to one of the three categories: productivity increases, creation of competitive advantage and enhancement of management effectiveness. In the next stage, factors with a significant influence on the achievement of the defined objectives (pressure points) are identified which fall into four classes: functional areas that have the greatest influence on reaching corporate goals (critical functions), professional groups that currently affect the achievement of objectives most (critical job families), key business processes for the attainment of aims (critical processes) and products with the highest impact on reaching objectives (critical products). In the last stage, profound analysis is conducted to select those IS investment alternatives that support the pressure points best. On this ground, the IS budget is allocated to critical areas, i.e. functions, job families, processes, or products. Other examples of this class include critical success factors [Rock79], the IS strategic grid [MaMa83, 74], process quality management [WaGW90, 106], Elliot's method [ElMe95] and Fitzgerald's method [Fitz98].

Several advantages of the NNC model can be highlighted. It helps to enhance the effectiveness of IS investments by aligning them to corporate objectives whose definition is part of the prescribed procedure. Since the range of potential investment areas is narrowed down, only a reduced number of alternatives has to be examined in the subsequent planning stages. Additionally, the comprehensibility of analysis is improved through the categorization of corporate objectives and success factors. On the other hand, the success factors are treated as if they were of equal importance. Furthermore, the present IS situation that reflects investment behavior in the past is insufficiently taken into account and the model implicitly assumes that increasing capital commitment leads to rising effectiveness of the IS [Rett96, 73].

\subsubsection{Corporate Processes-Related Approaches}

This class is exemplified through Retter's model which draws on the mapping of process chains and effect chains with the particular objective to discover both direct and indirect effects of a potential IS investment [ReBa95, Rett96, 103]. Process chains illustrate sequences of processes consisting 
of successive interdependent activities while effect chains depict the interrelationships between investment effects.

The model is divided into three main stages: (a) identification and development of process chains, (b) analysis of direct effects, and (c) identification and investigation of effect chains. In the first stage, process chains are mapped. Therefore, corporate processes affected by an IS investment are located and split into distinct activities for further analysis. The resulting map is then supplemented by marking the boundaries of organizational units and adding processes unaffected by the potential IS investment. In the second stage, direct effects are investigated. Therefore, changes in processes directly caused by the IS investment are estimated and analyzed. Conditions for the realization of the desired investment benefits should be regarded at this stage and borne in mind during planning. The third stage comprises the mapping of effect chains for which all significant effects caused by direct effects are located.

As for particular advantages, Retter's model attempts to locate direct, as well as indirect effects, and attempts to reveal the dependencies among them. One analysis focus lies on a necessary or possible restructuring of processes. Furthermore, changes in organizational units that are triggered by an IS investment can be discovered. However, the application of the model tends to be costly, especially for appraising competing and complex systems, even if the analysis effort might depend on the desired level of detail [Rett96, 106]. Furthermore, the development of effect chains implies that evaluators know, or at least can anticipate, the majority of causal relationships between direct and indirect effects. The high number of potentially confounding variables may thus add to the uncertainty involved in the application of this model. Further models of this class are utility effect chains [Anse84, 25], process analysis [Schu93; Dave93, Ch.3] and the van-Wegen-de-Haag model [WeHa96].

\subsubsection{Customer-Related Approaches}

The customer resource life cycle (CRLC) model can serve as one example of this class [IvLe84]. It starts from the notion that the acquisition of a resource by a customer requires a considerable investment of time and effort and corresponds to a staged life cycle model, termed customer resource life cycle. All in all, the model comprises 13 stages from the establishment of requirements to the monitoring of the resources' usage. It is argued that if a supplier can assist a customer in managing this life cycle, the supplier may be able to differentiate himself from competitors on the base of enhanced customer service and the introduction of switching costs. The value of an IS or its components is seen in its ability to support several or all stages of the life cycle. Being a generator of ideas [HaRo94, 265], the model aims to discover improvement potential of IS by either mapping existing applications into new settings or by identifying new applications. Additional customer-related models were suggested by Notowigdo [IvLe84] and Grosse [Nage90, 118].

The main advantages of the CRLC model are that it makes the customer the center of attention and that it leads to a process in which IS investment opportunities are proactively sought [HaRo94, 265]. However, the model may only be helpful for companies following a differentiation strategy through enhanced customer service and might prove to be too inflexible in many cases because not all stages apply equally well to all circumstances. No empirical support for the suggested model is provided. Furthermore, taking into account that the actual customer does not participate in the proposed analysis procedure, the model is at second glance only limitedly customer-oriented.

\subsubsection{Change Management-Related Approaches}

The techniques in this class particularly address aspects of managing change induced by IS investments. Their logic is reflected by an approach suggested by Avgerou [Avge95; cf. also LuGN79]. In essence, Avgerou's approach constitutes a framework to organize the process of evaluation in a highly political context and is based on four main principles. First, the task of the evaluators is to organize and support a dialectic evaluation process, to assess methodically aspects of the system under evaluation that are regarded as appropriate by stakeholders and to identify stakeholders' oversights. Second, the evaluation process is participative, allowing all stakeholders to express their views and supporting them to defend their position. Third, the criteria of evaluation are adjusted to the specific context and include all the concerns of the stakeholders. Fourth, the objective is to reach a consensual decision by accepting and possibly modifying plans and proposals for new systems.
For the implementation of this process, Avgerou refers to a methodology where the evaluator essentially acts as a mediator between different interest groups [GuLi89, 72]. Traditional evaluation techniques are applied throughout this process as needed, to clarify or support arguments of the groups. For a successful application of this procedure, the parties need to possess a certain level of communication skills and have to show the willingness to genuinely participate in the process, to share power, to reconsider their value positions, and to commit themselves to changes decided by the process. A predecessor of Avgerou's method is the work of the "Scandinavian school" with the model 'ISAC' [LuGN72], variants are the soft systems methodology [Avge95] and the situated hermeneutic evaluation [JoHu01].

Advantages of these methods are that they explore different value perceptions and foster mutual understanding of involved parties through the exchange of opinions whereby potential resistance to change may be mitigated. Consequently, it supplements traditional formal-rational approaches by regarding the political dimension of ISE as well as aspects of change. This is why several researchers see a growing trend in the adoption of this perspective [Wals95]. However, some of the assumptions mentioned above are likely to not be met in practice. The approach might be rejected by practitioners because of the incompatibility to the culture of many organizations and because of the prevailing perception of IS development and evaluation as a technical task [Avge95]. Moreover, research noticed general communication problems between evaluators [Hube99] and winner-loser situations might make consensus decisions difficult. The application of the approach is not conducive to quick decision-making due to the time required for its application.

\subsection{Usability of the Approaches}

Table 3 summarizes key characteristics of the reviewed approaches. Accordingly, no approach is universally applicable due to own distinct limitations. Thus, some authors suggested combining approaches in order to arrive at a more comprehensive state of ISE [Schu93]. The realization of this idea is restricted by the effort involved and the bounded compatibility of the approaches as the output produced by one method does not necessarily match the input required by another. 


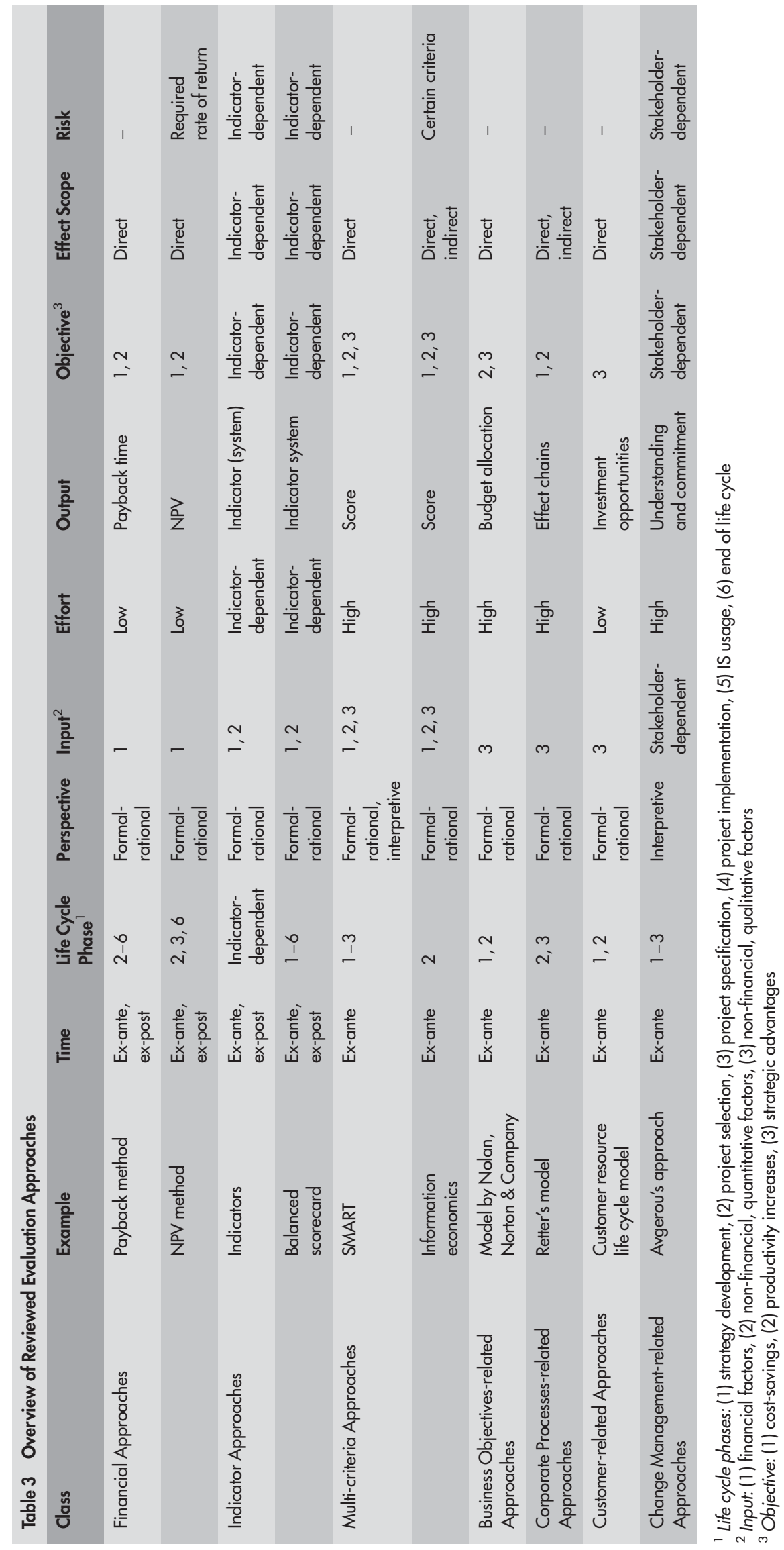

Formal-rational approaches are dominating the field which may reflect that early researchers in this area were mainly technologists, followed by accountants [Powe92]. The oversupply of these methods is also problematic if it induces a neglect of social, political and organizational aspects in evaluation activities. It was argued that the success of an IS is not determined by technical aspects alone but to a large extent by "people problems" [SyWa91, 84], organizational issues and market aspects [RMSE00, Ch. 8]. Ignoring these social and managerial elements can consequently be a threat to any evaluation endeavor because effects are assessed that might, if such elements are not addressed appropriately, never come true: "... there are many examples of good technical solutions being introduced, only to find that anticipated benefits were not realized because the social elements were not fully considered" [JoHu01, 191].

Qualitative IS features are treated differently by the reviewed approaches. Methods belonging to the class of effect-locating approaches have their primary focus on qualitative factors and generally make no attempt to break down these factors to numbers. In contrast, effect-assessing approaches either include qualitative aspects as far as they are quantifiable, or exclude them. In both cases, excluding, or not properly including, qualitative aspects implies the hazard of costly misjudgments [AnWe99; RMSE00, 287]. For this reason, German government agencies, for instance, tend to rely on both NPV and SMART for the assessment of their IS investments [Röth01].

Adding to the list of deficiencies, the body of approaches limitedly provides facilities for the analysis of indirect effects, often experienced in practical IS management. This is surprising inasmuch as, for instance, unforeseen indirect costs not seldom cause cost overruns leading in extreme cases to the cancellation of whole projects. Moreover, few approaches explicitly comprise facilities for risk assessment. However, it might be questioned if the incorporation of risk elements in ISE is generally possible. The analysis of risk requires the knowledge of either objective or subjective probabilities. As IS investments are often organization-specific undertakings, objective probabilities are likely to be unavailable or to bear validity problems in many situations [PeSt03, 101]. The reliance on subjective probabilities involves problems of choosing capable experts and possibly aggregating the judgment of several persons [GoWr00, 296]. 
The handling of key ISE problems by the approaches is another point of interest. One substantial difficulty of ex-ante ISE is the estimation of several factors. First, the IS lifetime is hard to anticipate due to technological progress and the evolution of systems for which the approaches under review provide no support. Second, as already discussed above, a relative neglect of indirect or compound investment effects is a drawback of several approaches. Third, the identification of IS investment impacts is a general problem area addressed only by effect-locating approaches. However, their use involves the trade-off between precision and effort. Fourth, the hardly predictable evolution of IS benefits and sacrifices complicates ISE but is not addressed by the approaches.

Data collection issues are treated differently. While effect-locating approaches partly aim at generating data for appraisal purposes, effect-assessing approaches assume the availability of basic data and thus ignore this aspect. Moreover, the boundaries of an IS are hard to determine, as IS are frequently being extended by adding components and by being integrated into other systems. Although a clearly-defined evaluation object is a prerequisite for an accurate appraisal, evaluation approaches do not assist the definition of a system's reach [Renk00].

Conscious and unconscious judgmental bias can be a serious threat to the objectivity of evaluation postulated by the formalrational perspective. In case of conscious bias, approaches are, while being degraded to instruments for rationalizing alreadymade decisions, likely to lose their evaluation potential. On the other hand, methods such as SMART can help to identify unconscious bias and to avert its negative consequences by making implicit assumptions of the evaluators explicit. Another evaluation problem lies in the communication between evaluators. Although methods such as IE can foster the exchange of ideas between evaluators, they obviously cannot provide a mechanism to avert misunderstandings and confused purposes between the involved persons.

\section{Evaluation in Practice}

The variety of available evaluation techniques raises the question of which approaches do practitioners actually employ and what problems do they encounter thereby. The analysis of IS literature re- vealed only 12 relevant studies with acceptable sample sizes of at least 15 interviews or 50 questionnaires which focused exclusively on the US and UK region [Baco92; BaSt98; BlBr88; CADF97; DoKi01; EzIR98; FaLT92; FoWa99; RyHa00; Tam92; WiKK92; WiLe91]. For reasons of space, only their key findings are discussed below whereas a summary of all studies is provided by [Walt03]

Essentially, empirical findings indicated an increase in corporate evaluation activities since 1988 and confirmed the following statement "[...] the mystique which protected some budgets is no longer credible. Evaluation is demanded and done." [FaLT99, 203]. The most popular techniques in practice were financial approaches, particularly cost-benefit analysis and the payback method. Correspondingly, IS investments were predominantly assessed according to financial criteria with managers especially envisaging cost-savings. This focus on financial aspects, however, did not mean the total ignorance of non-financial factors in evaluation processes. While some of these factors were taken into account, other factors, including risk and "soft" hidden costs, were disregarded.

Practitioners named the identification of benefits, the quantification of benefits, and the estimation of costs and returns as main problems associated with the appraisal of IS investments by means of evaluation approaches. Lack of time, lack of data, lack of interest and interpretation difficulties of results were stated as minor problems. It was further reported that evaluation was, in many cases, additionally complicated through political factors, different perceptions of "value" and communication difficulties. Managers were criticized for their susceptibility to fashions and their neglect of social factors in evaluation.

\section{Conclusions}

The objectives of this paper were (1) to identify approaches suitable for the ex-ante evaluation of IS investments, (2) to discuss their effectiveness, and (3) to examine their meaning for evaluation practice.

A comprehensive review of English and German IS literature yielded numerous distinct approaches suggested for an application to ISE. The dominating type were formal-rational approaches which aim to determine the objective economic value of an IS investment to an organization irrespective of the context. Few interpretive methods considering the political and social aspects of ISE were proposed.

It was argued that all identified approaches together can meet a wide spectrum of requirements whereas each has its individual advantages and drawbacks. The possibility of combining them is restricted by their bounded compatibility and in many cases by the effort involved. A consideration of indirect investment effects, qualitative factors and risk is not sufficiently supported by several approaches. Additionally, general ISE problems including particularly difficulties in forecasting and determining a system's reach may often reduce the effectiveness of approaches.

Only 12 empirical studies on ISE in practice were available. Their findings indicate that mainly financial approaches, despite their identified limitations, are applied for evaluation purposes. As explanations for these results, their easy application, their good communicability and the existence of a general norm were suggested.

To overcome current deficiencies in the field further work is required. Suitable tasks for future research include the development of a selection framework for approaches as well as the exploration of ways to combine them and to incorporate indirect effects, qualitative factors and risk. Indepth research on the integration of exante and ex-post evaluation, for instance by establishing facilities for the storage of evaluation data [Spit00; Krcm03, Ch.3.4], is also needed to enable a 'holistic' ISE whereas more empirical studies could help to understand why and with which problems practitioners employ evaluation approaches. This could ultimately help to move the field of research on ISE forward which is still one of the most challenging tasks in IT management.

\section{References}

[AgTD92] Agarwal, R.; Tanniru, M. R.; Dacruz, $M$.: Knowledge-Based Support for Combining Qualitative and Quantitative Judgments in Resource Allocation Decisions. In: Journal of Management Information Systems 9 (1992) 1, pp. $165-184$.

[Ahit80] Abituv, N.: A Systematic Approach Toward Assessing the Value of an Information System. In: MIS Quarterly 4 (1980) 4, pp. 61-75.

[Alpa02] Alpar, P.; Grob, H. L.; Weimann, P.; Winter, R.: Anwendungsorientierte Wirtschaftsinformatik: strategische Planung, Entwicklung und Nutzung von Informations- und Kommunikationssystemen. 3. ed., Vieweg, Braunschweig 2002. 
[Anse84] Anselstetter, R.: Betriebswirtschaftliche Nutzeffekte der Datenverarbeitung: Anhaltspunkte für Nutzen-Kosten-Schätzungen. Springer, Berlin 1984.

[AnWe99] Anandarajan, A.; Wen, H. J.: Evaluation of Information Technology Investment. In: Management Decision 37 (1999) 4, pp. 329-337.

[ArIn99] Arribas, E. H.; Inchusta, P. J. S.: Evaluation Models of Information Technology in Spanish Companies: A Cluster Analysis. In: Information \& Management 36 (1999) 3, pp. 151-164.

[Arno95] Arnold, V.: Discussion of An Experimental Evaluation of Measurements of Information System Effectiveness. In: Journal of Information Systems 9 (1995) 2, pp. 85-91.

[AvCP99] Avison, D. E.; Cuthbertson, C. H.; Powell, P.: The Paradox of Information Systems: Strategic Value and Low Status. In: Journal of Strategic Information Systems 8 (1999) 4, pp. 419-445.

[Avge00] Avgerou, C.: Information Systems: What Sort of Science Is It? In: Omega 28 (2000) 5, pp. 567-579.

[Avge95] Avgerou, C.: Evaluating Information Systems by Consultation and Negotiation. In: International Journal of Information Management 15 (1995) 6, pp. 427-436.

[Baco92] Bacon, J. C.: The Use of Decision Criteria in Selecting Information Systems/Technology Investments. In: MIS Quarterly 16 (1992) 3, pp. 335-353.

[BaFr99] Baumöl, U.; Frie, T.: Ein integriertes IVControlling-Instrumentarium für Investitionsund Betriebsphase. In: von Dobschütz, L.; Baumöl, U.; Jung, R. (eds.): IV-Controlling aktuell: Leistungsprozesse - Wirtschaftlichkeit - Organisation. Gabler, Wiesbaden 1999, pp. 123-152.

[BaRe00] Bannister, F.; Remenyi, D.: Acts of Faith: Instinct, Value and IT Investment Decisions. In: Journal of Information Technology 15 (2000) 3, pp. 231-241.

[BaRe96] Baumöl, U.; Reichmann, T.: Kennzahlengestütztes IV-Controlling. In: Controlling 8 (1996) 4, pp. 204-211.

[BaSt98] Ballantine, J.; Stray, S.: Financial Appraisal and the IS/IT Investment Decision Making Process. In: Journal of Information Technology 13 (1998) 1, pp. 3-14.

[Bede85] Bedell, E. F.: The Computer Solution. Dow Jones-Irwin, Homewood 1985.

[BlBr88] Blackler, F; Brown, C.: Theory and Practice in Evaluation: The Case of the New Information Technologies. In: Bjørn-Andersen, $N$.; Davis, G. B. (eds.): Information Systems Assessment: Issues and Challenges. North-Holland, Amsterdam 1988, pp. 351-367.

[BrHi98] Brynjolfsson, E.; Hitt, L. M.: Beyond the Productivity Paradox. In: Communications of the ACM 41 (1998) 8, pp. 49-55.

[BrMy03] Brealey, R. A.; Myers, S. C.: Principles of Corporate Finance. 7. ed., Irwin McGrawHill, Boston 2003

[Buss83] Buss, M. D. J.: How to Rank Computer Projects. In: Harvard Business Review 61 (1983) 1, pp. 118-125.

[CADF97] Clegg, C.; Axtell, C.; Damodaran, L.; Farbey, B.; Hull, R.; Lloyd-Jones, R.; Nicholls, J.; Sell, R.; Tomlinson, C.: Information Technology: A Study of Performance and the Role of Human and Organizational Factors. In: Ergonomics 40 (1997) 9, pp. 851-871
[ChKa00] Chircu, A. M.; Kauffman, R. J.: Limits to Value in Electronic Commerce-Related IT Investments. In: Journal of Management Information Systems 17 (2000) 2, pp. 59-80.

[CoSC01] Computer Sciences Corporation: 14th Annual Survey of IS Management Issues. CSC, El Sugundo 2001

[DaKa00] Davern, M. J.; Kauffman, R. J.: Discovering Potential and Realizing Value from Information Technology Investments. In: Journal of Management Information Systems 16 (2000) 4, pp. 121-143.

[Dave93] Davenport, T. H.: Process Innovation Reengineering Work through Information Technology. Harvard Business School Press, Boston 1993.

[DeRi02] Dehning, B.; Richardson, V. J.: Returns on Investments in Information Technology: A Research Synthesis. In: Journal of Information Systems 16 (2002) 1, pp. 7-30.

[DoKi01] Doherty, N.; King, M.: The Treatment of Organisational Issues in Systems Development Projects: The Implications for the Evaluation of Information Technology Investments. http:// www.iteva.rug.nl/ejise/vol4/papers/Organisational \%20Issues \%20Evaluation.htm, 2001-03-01, as of 2004-01-27.

[ElMe95] Elliot, S.; Melhuish, P.: A Methodology for the Evaluation of IT for Strategic Implementation. In: Journal of Information Technology 10 (1995) 2, pp. 87-100.

[EzIR98] Ezingeard, J.-N.; Irani, Z.; Race, P.: Assessing the Value and Costs Implications of Manufacturing Information and Data Systems: An Empirical Study. In: European Journal of Information Systems 7 (1998) 4, pp. 252-260.

[FaLT92] Farbey, B.; Land, F.; Targett, D.: Evaluating Investments in IT. In: Journal of Information Technology 7 (1992) 2, pp. 109-122.

[FaLT93] Farbey, B.; Land, F.; Targett, D.: How to Assess Your IT Investment: a Study of Methods and Practice. Butterworth-Heinemann, Oxford et al. 1993.

[FaLT99] Farbey, B.; Land, F.; Targett, D.: Moving IS Evaluation Forward: Learning Themes and Research Issues. In: Journal of Strategic Information Systems 8 (1999) 2, pp. 189-207.
[Fitz98] Fitzgerald, G.: Evaluating Information Systems Projects: A Multidimensional Approach. In: Journal of Information Technology 13 (1998) 1, pp. 15-27.

[FoWa99] Fowler, A.; Walsh, M.: Conflicting Perceptions of Success in an Information Systems Project. In: Journal of Project Management 17 (1999) 1, pp. 1-10.

[GoWr00] Goodwin, P.; Wright, G.: Decision Analysis for Management Judgment. 2. ed., Wiley, Chichester 2000.

[GrBr97] Van Grembergen, W.; Van Bruggen, R.: Measuring and Improving Corporate Information Technology through the Balanced Scorecard. http://www.iteva.rug.nl/ejise/vol1/issue1/ paper3/ fr_pap.html, 1997-12-01, as of 2004-0127.

[GuLi89] Guba, E. G.; Lincoln, Y. S.: Fourth Generation Evaluation. Sage, Beverly Hills 1989.

[HaRo94] Hares, J.; Royle, D.: Measuring the Value of Information Technology. Wiley, Chichester 1994

[Hauf89] Haufs, P.: DV-Controlling: Konzeption eines operativen Instrumentariums aus BudgetsVerrechnungspreisen-Kennzahlen. Physica, Heidelberg 1989.

[Hein96] Heinrich, L. J.: Informationsmanagement: Planung, Überwachung und Steuerung der Informationsstruktur. Oldenbourg, München 1996.

[Hoga80] Hogarth, R. M.: Judgement and Choice. Wiley, Chichester 1980.

[HoGr91] Hochstrasser, B.; Griffiths, C.: Controlling IT Investment: Strategy and Management. Chapman \& Hall, London 1991.

[Hube99] Huber, H.: Die Bewertung des Nutzens von IV-Anwendungen. In: von Dobschütz, $L$.; Baumöl, U.; Jung, R. (eds.): IV-Controlling aktuell: Leistungsprozesse-Wirtschaftlichkeit-Organisation. Gabler, Wiesbaden 1999, pp. 107122.

[Iran02] Irani, Z.: Information Systems Evaluation: Navigating Through the Problem Domain. In: Information \& Management 40 (2002) 1, pp. $11-$ 24.

[IrLo02] Irani, Z.; Love, P. E. D.: Developing a Frame of Reference for Ex-Ante IT/IS Invest-

\section{Abstract}

\section{Approaches to the Ex-ante Evaluation of Investments into Information Systems}

This paper critically reviews approaches for the evaluation of investments in information systems prior to their implementation. First, the ground for the review is prepared by examining characteristics of evaluation, information systems and value. A classification of the numerous evaluation approaches identified in English and German literature is then presented. Examples of each class are reviewed and their advantages and drawbacks are discussed. Their use in evaluation practice is analyzed through the examination of empirical studies and directions for future research are given.

Keywords: Information Systems, Information Technology, Evaluation, Value, Benefit, Performance, Success, Efficiency 
ment Evaluation. In: European Journal of Information Systems 11 (2002) 1, pp. 74-82.

[IvLe84] Ives, B.; Learmonth, G. P.: The Information System as Competitive Weapon. In: Communications of the ACM 27 (1984) 12, pp. $1193-1201$

[JoHu01] Jones, S.; Hughes, J.: Understanding IS Evaluation as a Complex Social Process: A Case Study of a UK Local Authority. In: European Journal of Information Systems 10 (2001) 4, pp. 189-203.

[KaNo92] Kaplan, R. S.; Norton, D. P.: The Balanced Scorecard-Measures That Drive Performance. In: Harvard Business Review 70 (1992) 2 , pp. 71-79.

[KiRo78] King, W. R.; Rodriguez, J. I.: Evaluating Management Information Systems. In: MIS Quarterly 2 (1978) 3, pp. 43-51.

[Klei80] Kleijnen, J. P.: Computers and Profits: Quantifying Financial Benefits of Information. Addison-Wesley, Reading 1980.

[Krcm03] Krcmar, H.: Informationsmanagement. 3. ed., Springer, Berlin 2003.

[Kütz99] Kütz, M.: Ein Konzept für das IV-Benchmarking. In: von Dobschütz, L.; Baumöl, U.; Jung, R. (eds.): IV-Controlling aktuell: Leistungsprozesse-Wirtschaftlichkeit-Organisation. Gabler, Wiesbaden 1999, pp. 23-52.

[Linc88] Lincoln, T.: Retrospective Appraisal of Information Technology Using SESAME. In: Bjørn-Andersen, N.; Davis, G. B. (eds.): Information Systems Assessment: Issues and Challenges. North-Holland, Amsterdam 1988, pp. 299-312.

[LuGN79] Lundeberg, M.; Goldkubl, G.; Nilson, A.: A Systematic Approach to Information Systems Development - Part I: Introduction. In: Information Systems 4 (1979), pp. 1-12.

[MaFl00] Marsh, L.; Flanagan, R.: Measuring the Costs and Benefits of Information Technology in Construction. In: Engineering, Construction and Architectural Management, 7 (2000) 4, pp. 423-435.

[MaMa83] MacFarlan, F. W.; MacKenney, J. L.: Corporate Information Systems Management: The Issues Facing Senior Executives. Dow Jones-Irwin, Homewood 1983.

[MaSz99] Mahmood, M. A.; Szewczak, E. J.: Measuring Information Technology Investment Payoff: Contemporary Approaches. Idea Group Publishing, Hershey 1999.

[Nage90] Nagel, K.: Nutzen der Informationsverarbeitung: Methoden zur Bewertung von strategischen Wettbewerbsvorteilen, Produktivitätsverbesserungen und Kosteneinsparungen. 2. ed., Oldenbourg, München 1990.

[Ott93] Ott, H. J.: Wirtschaftlichkeitsanalyse von EDV-Investitionen mit dem WARS-Modell am Beispiel der Einführung von CASE. In: Wirtschaftsinformatik 35 (1993) 6, pp. 522-531.

[PaBe88] Parker, M. M.; Benson, R. J.: Information Economics: Linking Business Performance to Information Technology. Prentice-Hall, Englewood 1988.

[PeSt03] Perridon, L.; Steiner, M.: Finanzwirtschaft der Unternehmung. 12. ed., Vahlen, München 2003.
[Pico87] Picot, A.: Bürokommunikation: Leitsätze für den Anwender. 3. ed., AIT, Hallbergmoos 1987.

[Powe92] Powell, P.: Information Technology Evaluation: Is It Different? In: Journal of the Operational Research Society 43 (1992) 1, pp. 29-42.

[ReBa95] Retter, G.; Bastian, M.: Kombination einer Prozess- und Wirkungskettenanalyse zur Aufdeckung der Nutzenpotentiale von Informations- und Kommunikationssystemen. In Wirtschaftsinformatik 37 (1995) 2, pp. 117-128.

[ReBe97] Renkema, T. J.; Berghout, E.: Methodologies for Information Systems Investment Evaluation at the Proposal Stage: A Comparative Review. In: Information and Software Technology 39 (1997) 1, pp. 1-13.

[Renk00] Renkema, T. J.: The IT Value Quest: How to Capture the Business Value of IT-Based Infrastructure. Wiley, Chichester 2000.

[Rett96] Retter, G.: Ein prozeßorientiertes Wirtschaftlichkeitsanalyseverfahren zur Bewertung von Informationssystemen anhand strategischer Wirkungen. Rheinisch-Westfälische Technische Hochschule, Aachen 1996.

[RMSE00] Reichwald, R.; Möslein, K.; Sachenbacher, H.; Engelberger, H.: Telekooperation: Verteilte Arbeits- und Organisationsformen. 2. ed., Springer, Berlin et al. 2000.

[Rock79] Rockart, J. F.: Chief Executives Define Their Own Data Needs. In: Harvard Business Review 57 (1979) 2, pp. 81-93.

[Röth01] Rötbing, P.: WiBe21 - Empfehlung zur Durchführung von Wirtschaftlichkeitsbetrachtungen in der Bundesverwaltung, insbesondere beim Einsatz der IT. http://www.kbst.bund.de/ Anlage300441/KBSt-Schriftenreihe+-

Band $+52+(1 \% 2 \mathrm{c} 3+\mathrm{MB})$.pdf, 2001-05-01, as of 2004-01-27.

[RyHa00] Ryan, S. D.; Harrison, D. A.: Considering Social Subsystem Costs and Benefits in Information Technology Investment Decisions: A View from the Future of Anticipated Payoffs. In Journal of Management Information Systems 16 (2000) 4, pp. 11-40.

[Sant91] Dos Santos, B. L.: Justifying Investments in New Information Technologies. In: Journal of Management Information Systems 7 (1991) 4, pp. 71-90.

[SaSc78] Sassone, P. G.; Schaffer, W. A.: Cost-Benefit Analysis. Academic Press, New York 1978.

[SaSc86] Sassone, P. G.; Schwartz, A. P.: Cost-Justifying OA. In: Datamation 1986-02-15, pp.8388.

[ScBö89] Schulz, H.; Bölzing, D.: Erfassung des in direkten Nutzens von CIM-Investitionen. In Die Betriebswirtschaft 49 (1989) 5, pp. 611-621.

[Schä88] Schäfer, G. (ed.): Functional Analysis of Office Requirements: A Multiperspective Approach. Wiley, Chichester 1988.

[Schu93] Schumann, M.: Wirtschaftlichkeitsbeurteilung für IV-Systeme. In: Wirtschaftsinformatik 35 (1993) 2, pp. 167-178.

[SeSm00] Serafeimidis, V.; Smithson, S.: Information Systems Evaluation in Practice: A Case Study of Organizational Change. In: Journal of Information Technology 15 (2000) 2, pp. 93 105.
[Sieg90] Siegwart, H.: Kennzahlen für die Unternehmungsführung. Haupt. Bern 1990.

[SmHi98] Smithson, S.; Hirschbeim, R.: Analysing Information System Evaluation: Another Look at an Old Problem. In: European Journal of Information Systems 7 (1998) 3, pp. 158-174

[Spit00] Spitta,T.: Kostenrechnerische Grundlagen für das IV-Controlling. Kostenrechnungspraxis 44 (2000) 5, pp. 279-288.

[StGR97] Stickel, E.; Groffmann, H.-D.; Rau, $K .-H$. (eds.): Gabler-Wirtschaftsinformatik-Lexikon. Gabler, Wiesbaden 1997.

[Stic01] Stickel, E.: Informationsmanagement. Oldenbourg, München 2001.

[SyWa91] Symons, V.; Walsham, G.: The Evaluation of Information Systems: a Critique. In: Veryard, R. A. (ed.): The Economics of Information Systems and Software. Butterworth-Heinemann, Oxford 1991, pp. 71-88.

[TaFM00] Taudes, A.; Fenerstein, M.; Mild, A.: Options Analysis of Software Platform Decisions: A Case Study. In: MIS Quarterly 24 (2000) 2, pp. $227-243$

[Tam92] Tam, K. Y.: Capital Budgeting in Information Systems Development. In: Information \& Management 23 (1992) 3, pp. 345-357.

[Tewa00] Tewald, C.: Die Balanced Scorecard für die IV. In: von Dobschütz, L. (ed.): IV-Controlling. Gabler, Wiesbaden 2000, pp. 621-640.

[WaGW90] Ward, J.; Griffith, P.; Whitmore, P. Strategic Planning for Information Systems. Wiley, Chichester 1990.

[Wals95] Walsham, G.: The Emergence of Interpretivism in IS Research. In: Information Systems Research 6 (1995) 4, pp. 376-394.

[Walt03] Walter, S. G.: The Practical Use of IS Evaluation Approaches. Excerpt from: Walter, S. G. Approaches to the Ex-ante Evaluation of Information Systems. Diploma Thesis, University of Bielefeld, Faculty of Business and Economics, May 2003.

http://www.wiwi.uni-bielefeld.de/ spitta/forschung/EmpStudiesExAnte.pdf, 2003-05-16, as of 2004-01-27.

[WeHo96] van Wegen, B.; de Hoog, R.: Measuring the Economic Value of Information Systems. In: Journal of Information Technology 11 (1996) 3, pp. 247-260.

[WiKK92] Wilner, N.; Koch, B.; Klammer, T.: Justification of High Technology Capital Investments- an Empirical Study. In: The Engineering Economist 37 (1992) 4, pp. 341-353.

[WiLe91] Willcocks, L.; Lester, S.: Information Systems Investments: Evaluation at the Feasibility Stage of Projects. In: Technovation 11 (1991) 5, pp. 283-302.

[ZeJo99] van der Zee, J. T. M.; de Jong, B.: Alignment is Not Enough: Integrating Business and Information Technology Management with the Balanced Business Scorecard. In: Journal of Management Information Systems 16 (1999) 2, pp. 137-156. 